\title{
$\begin{array}{ll}\text { Research Square } & \begin{array}{l}\text { Preprints are preliminary reports that have not undergone peer review. } \\ \text { They should not be considered conclusive, used to inform clinical practice, } \\ \text { or referenced by the media as validated information. }\end{array}\end{array}$
}

\section{Glycaemic control and complications in people with diabetes: sex and socioeconomic status differences in the city of Madrid}

\section{Sara Ares-Blanco ( $\nabla$ sara.ares@salud.madrid.org)}

Federica Montseny Health Centre, Gerencia Asistencial Atención Primaria, Servicio Madrileño de Salud. PhD student at Medical Specialties and Public Health, University Rey Juan Carlos, Madrid

\section{Elena Polentinos-Castro}

Research Unit. Gerencia de Atención Primaria, Servicio Madrileño de Salud, Madrid. REDISSEC ISCIII. Medical Specialties and Public Health Department, University Rey Juan Carlos, Madrid

\section{Francisco Rodríguez-Cabrera}

Public Health Teaching Unit. National School of Public Health. Instituto de Salud Carlos III

\section{Pedro Gullón}

Public Health and Epidemiology Research Group, Universidad de Alcalá, Madrid

Luis Sánchez Perruca

Research Unit. Gerencia de Atención Primaria, Servicio Madrileño de Salud, Madrid. REDISSEC ISCIII, Madrid

Manuel Franco Tejero

Public Health and Epidemiology Research Group, Universidad de Alcalá, Madrid, Spain. Department of Epidemiology, Johns Hopkins Bloomberg School of Public Health, Baltimore, Maryland

Isabel del Cura González

Research Unit. Gerencia de Atención Primaria, Servicio Madrileño de Salud, Madrid. REDISSEC ISCIII. Medical Specialties and Public Health Department, University Rey Juan Carlos, Madrid

\section{Research Article}

Keywords: Type 2 diabetes mellitus, sex, primary healthcare, healthcare disparities, observational study

Posted Date: April 7th, 2021

DOl: https://doi.org/10.21203/rs.3.rs-350338/v1

License: (-) (i) This work is licensed under a Creative Commons Attribution 4.0 International License. Read Full License 


\section{Abstract}

Background: Differences in complications and multimorbidity for people with type 2 diabetes mellitus (T2D) have been found according to patient sex and socioeconomic status (SES). We analysed the association between sex and SES with glycaemic and cardiovascular control in diabetic primary care patients from the whole city of Madrid.

Methods: This was an observational, descriptive, retrospective, multicenter study with an analytical approach within the Heart Healthy Hood Project (HHH). A total of 68,535 T2D patients between 40-75 years who were living in the municipality of Madrid were included. Age, sex, area-level SES (in quintiles from least to most wealth), tobacco use, comorbidities, complications, and health center characteristics were collected from primary care electronic health records during 2017-2018. The primary outcome was glycaemic control indicated by an $\mathrm{HbA} 1 \mathrm{c} \leq 7 \%$. The secondary outcomes were combined control target (HbA1c $\leq 7 \%$, blood pressure (BP), $<140 / 90 \mathrm{~mm} \mathrm{Hg}, \mathrm{LDL}<100 \mathrm{mg} / \mathrm{ml}$ ) and body mass index (BMl) $<30 \mathrm{~kg} / \mathrm{m} 2$ ). Descriptive, bivariate analyses and multilevel logistic regression models analyzed factors associated with suboptimal glycaemic control.

Results: The mean age was 62.7 years old, $43,2 \%$ were female. Glycaemic control was achieved by $63 \%$ of patients. Women had better glycaemic control than men $(64.2 \%$ vs $62.4 \%)$. Those who were in quintile 1 of SES achieved glycaemic control more often than those in quintile 5 (65.9\% vs $59.7 \%)$. The optimal combined target ( $\mathrm{HbA1c}, \mathrm{BP}, \mathrm{LDL}$ ) was reached by $10 \%$ of patients (women: $9.3 \%$ vs men: $11.2 \%$ ), especially those in quintile 5 . If $\mathrm{BMl}<30 \mathrm{~kg} / \mathrm{m}^{2}$ was added, the combined target attainment rate decreased to $6.6 \%$. In the adjusted regression model, we found that sex (AOR:0.97, 95\% Cl: 0.94-1.01) was not related with suboptimal glycaemic control but being part of quintile 4 (AOR: 1.02, 95\% Cl: 1.06-1.26) and 5 (AOR: 1.20, 95\% Cl: 1.10-1.32) of SES was associated with not reaching the glycaemic goal.

Conclusions: Suboptimal glycaemic and combined control were associated with being less affluent but not with sex in the whole population of people with diabetes in the city of Madrid. Public policies and doctors should take social determinants into account to reduce social and health inequalities.

\section{Background}

It is estimated that type 2 diabetes (T2D) affects 463 million people worldwide. Overall, $9.3 \%$ of adults suffer from diabetes. The prevalence varies with sex: men have a higher prevalence than women (9.6\% vs 9.0\%) (1). T2D prevalence not only increases with age but also depends on social factors, such as education, income, or neighbourhood socioeconomic status (SES) (2). Patients with T2D have increased risk of mortality for all other conditions in comparison to patients without diabetes (3), especially in women (4).

To achieve optimal control of this condition, clinical guidelines recommend maintaining $\mathrm{HbA} 1 \mathrm{c}<7 \%$, blood pressure $\leq 140 / 90 \mathrm{~mm} \mathrm{Hg}$, and a body mass index $<25 \mathrm{~kg} / \mathrm{m}^{2}$ (BMI). The LDL cholesterol target has changed over the years because of the different prevalence of cardiovascular disease worldwide. Patients who have a moderate cardiovascular risk according to a recognized score are recommended to start statins $(5,6)$. Although the objectives are clear, the targets for optimal control are not the same in each country, and even in the best situation, only $2 / 3$ of patients can reach them $(7,8)$. Nevertheless, this variability between countries could be explained by the differences in study design and study populations (9). Suboptimal glycaemic control increases the risk of complications such as stroke and retinopathy progression. Some studies found that patients whose HbA1c is outside the range of 6-8\% have more cardiovascular complications (10), more visits to the family doctor (11), more admissions to the hospital resulting from complications (12), and higher mortality than those with $\mathrm{HbA1c}$ levels inside this range (13).

Recently, some studies have described not only the glycaemic control but the combined target of glycaemic control ( $\mathrm{HbA} 1 \mathrm{c}<7 \%$ )), blood pressure control $(\leq$ $140 / 90 \mathrm{~mm} \mathrm{Hg}$ ), and LDL (<100 mg/dl)(14) (15)(16) (17). These studies showed that only a small proportion of patients achieved a combined target. In the last years, social determinants as sex and SES has been added to this approach because both determinants influence both healthy behaviours and access to the health system (18-20). Little is known to decide which single target could help more the T2D management, Wan et al, have suggested that LDL target alone could decrease cardiovascular disease risk among T2D patients (21).

Studies on the onset of cardiovascular events in patients with T2D are inconsistent. Some studies found that men had a greater prevalence while women had poorer control of cardiovascular risk factors $(22,23)$, but other investigations did not detect the same results $(24,25)$. Complications such as mortality postmyocardial infarction were more frequent in diabetic women younger than 60 years; however, as patients aged, the differences between the sexes diminished (26).

In terms of secondary prevention, women are less likely to attain adequate control of cardiovascular risk factors $(16,27)$. In Spain, the incidence of myocardial infarction is greater in diabetic men than in diabetic women (28); however, the risk of developing stroke is higher in diabetic women independent of their cardiovascular factors (29). Amputations occur more frequently in men at an early age than in women, mainly in those with a lower SES, smokers and diabetic foot disease $(30,31)$. The prevalence of diabetic nephropathy is related to tobacco use, hypertension and retinopathy, particularly in men (32). An impairment of the glomerular filtration rate (33) and a high level of albuminuria have been reported in young diabetic men (34), although women have demonstrated more advanced renal chronic disease (35). Diabetic retinopathy appears throughout the evolution of T2D more frequently in women, but the risk of progression is minor (36). Fewer microvascular complications and mortality were found in patients who had university degrees, particularly among women (37). Regarding T2D patients in Spain, those living in more deprived areas have more T2D complications and more admissions to the hospital; those inequalities are greater in women (38).

The Spanish National Health System provides first contact, comprehensive, continuous, coordinated care (which is free at the point of care) to defined a population served by primary care centers. Patients have named family physicians who are responsible for delivering and coordinating their care. Private health insurance is only hired by $18 \%$ of citizens (39), some of these patients combine public primary care and private hospital services. The electronic health

Page 2/11 
record (EHR) has been used since 2002 in primary care in Madrid. It has been validated in previous studies that the EHR can be used to study risk factors and the evolution of different diseases (40).

This study aimed to analyse the differences in glycaemic control by sex and SES in people with diabetes in the whole city of Madrid. Secondary objectives were to describe the influence of sex and SES on the combined control target (HbA1c $\leq 7$, blood pressure $\leq 140 / 90 \mathrm{~mm} \mathrm{Hg}, \mathrm{LDL}<100 \mathrm{mg} / \mathrm{dl}, \mathrm{BMl}<30 \mathrm{Kg} / \mathrm{m}^{2}$ ) and to study the main complications in type 2 diabetic patients in primary care in Madrid city.

\section{Methods}

Study design: Observational, retrospective study based in primary care population.

Setting: In 128 health centre practices (HCP) in the whole city of Madrid (Spain), 3.22 million patients were attached from August 2017 until July 2018.

Study population: Patients with type 2 diabetes (EHR record of T90 ICPC-2) included in the Heart Healthy Hoods project (HHH) whose aim was to study the urban environment, cardiovascular health, and inequities in Madrid city (41). Inclusion criteria were: having at least one measure of HbA1c during 1-year period, aged between 40 and 75 years, patients who lived in Madrid city (Spain) and had a primary care EHR in the Madrid Regional Health System (public health system)

\section{Variables:}

\section{Outcomes}

The primary outcome measure was glycaemic control which was optimal if the $\mathrm{HbA1c} \leq 7 \%(53 \mathrm{mmol} / \mathrm{mol})$. For patients who had more than one measure during the period of the study, we calculated the mean of those values. The secondary outcome was combined control target ( $\mathrm{HbA} 1 \mathrm{c} \leq 7 \%$, blood pressure $(B P)<140 / 90 \mathrm{~mm} \mathrm{Hg}, \mathrm{LDL}<100 \mathrm{mg} / \mathrm{ml}$ and body mass index $(\mathrm{BMI})<30 \mathrm{~kg} / \mathrm{m} 2$ ) according to the guidelines.

\section{SES index}

The MEDEA deprivation index has been constructed as a socioeconomic status index in Spain (42) including 4 indicators: unemployment, low education level, the percentage of people who are manual workers and those who are working in temporary jobs in relation to the employed population. Patients were grouped by quintiles of the MEDEA deprivation index according to the Health centre practices area (each area included homes around the health centre, each area belongs to a national zoning system): quintile 1 st (less deprived), $5^{\text {th }}$ quintile (more deprived).

\section{Covariates}

Covariates were defined as sociodemographic variables (Age, sex, foreign-born), cardiovascular risk factors (smoking, hypertension, dyslipidaemia, obesity), complications (ischaemic heart disease, stroke, peripheral vascular disease, chronic renal failure, diabetic nephropathy, diabetic retinopathy), physical examination (systolic and diastolic BP, BMI) and laboratory data ( $\mathrm{HbA1c}, \mathrm{LDL}$, estimated glomerular filtration rate - calculated with CKD-EPI values, MDRD4 and levy rate-, and albuminuria). Laboratory results were estimated as the arithmetic mean of the individual determinations during the one-year period. Health care practice: we included a set of covariates that reflect the activity of the health care centres (number of family doctors and nurses, daily consultation rates of family doctors and nurses (patients/day), population assigned to the primary health center for family doctor and nurses).

Statistical analyses: Patient characteristics were summarized using descriptive statistics (means, standard deviations, medians, interquartile ranges, and proportions when appropriate based on the distribution). The prevalence of T2D is given as percentage and $95 \% \mathrm{Cl}$. Variables potentially associated with glycaemic control were assessed using mixed effects logistic regression, taking into account the aggregation of data by cluster (health centre where each area belongs to a national zoning system), adjusted by age, sex, and SES. All the tests were conducted at a significance level of 0.05 . The analysis was performed using STATA 15.1

Ethics Approval: The HHH global study was approved by Madrid Primary Care Research Committee and the Ethics in Research Committee of the Madrid Health Care System (ERC-2013-StG-336893). This work was additionally approved by the Ethics in Research Committee of the Ramón y Cajal Hospital at Madrid city (341/2018). Both Ethics Committees have waived the requirement of the informed consent for this study.

\section{Results}

Study population characteristics 113,265 had type 2 diabetes mellitus ( $8.5 \%, 95 \% \mathrm{Cl}$ : $0.084-0.085)$. Of those patients, 68,535 (60.5\%) had at least one check-up performed within the previous 12 months. Comparisons between those who had their HbA1c levels tested in the last year and those who had not can be checked in Additional file 1. The mean age was 62.7 years old, women comprised $43.2 \%$ of the total. $41 \%$ of population were classified in SES quintiles 4 and 5 . Glycaemic control was achieved by $63 \%$ of the sample. The characteristics of the study population are shown in Table 1 according to their achievement of targets.

At baseline, the prevalence of hypertension was higher in women (67.2\%), and there was an increasing trend from the quintile 1 to the quintile 5 of $5 \%$. Women had also more dyslipidaemia (62.7\%), men were more obese (51.1\%) and smokers (21.8\%). Characteristics of men and women separately can be found in Additional file 2 and 3 . 
Glycaemic control and cardiovascular risk factors target by sex and SES index. Optimal glycaemic control was achieved in $63.2 \%$ of the population; $64.2 \%$ of the female patients and $62.4 \%$ of male patients ( $p<0.001$ ) (Additional file 4 collects the characteristics of those who achieve $\mathrm{HbA} 1 \leq 7 \mathrm{mg} / \mathrm{dl}$ and those who do not). In case, the optimal glycaemic control was established till HbA1 $\leq 8.5 \mathrm{mg} / \mathrm{dl}, 90.4 \%$ of population achieved the target. An analysis comparing glycaemic control by SES index was conducted (Figure 1), the proportion of patients who achieved optimal glycaemic control declined from the quintile 1 to the quintile 5 , and there were small differences between females and males in all quintiles. The BP target ( $<140 / 90 \mathrm{~mm} \mathrm{Hg})$ was not achieved by $27.2 \%$ of the sample followed by $\mathrm{BMI}>30 \mathrm{Kg} / \mathrm{m}^{2}$ which was present at $26.8 \%$ of the population. LDL $>100 \mathrm{mg} / \mathrm{dl}$ was found in $24.6 \%$ of the patients especially on those in quintile 1 and 5 .

When we focused on T2D as an illness that is associated with cardiovascular risk factors (HbA1c, LDL and BP) and addressed T2D and cardiovascular risk factors together, we found that $11.2 \%$ of males and $9.3 \%$ of females achieved an optimal combined target level (HbA1c $\leq 7 \%$, LDL $<100 \mathrm{mg} / \mathrm{dl}$ and BP $<$ $140 / 90 \mathrm{~mm} \mathrm{Hg})(\mathrm{p}<0,001)$. Those in SES quintile 5 obtained better combined targets than those in SES quintile 1 (men: $13.4 \%$ vs $11.1 \%$, women: $10.6 \%$ vs $9.5 \%$ ). We added the objective $\mathrm{BMl}<30 \mathrm{~kg} / \mathrm{m}^{2}$ to that target, the patients who achieved it fell to $6.6 \%$, and there were differences between sexes. Women had worst combined targets regardless of the SES index (Additional file 2 and 3 ).

Glycaemic control and complications by SES index. All complications were more frequent in men, and men in the SES quintile 1 had more coronary heart disease and strokes than men in the other quintiles. In the case of women, our findings showed that those in the quintile 5 had more coronary heart disease, strokes and retinopathy.

Multilevel analysis was performed to analyse not only the effect of sex and SES index (individual level) on suboptimal glycaemic but the effect of the practice (level 2) ( table 2). The health centre, the number of patients attending each health centre every day and the number of doctors/nurses did not explain the prevalence of optimal glycaemic control in our study (practice's characteristics can be seen in Additional file 5). Firstly, we tested the interaction sex and deprivation index, there were no interaction between the two variables. We built a model for men and women separately to describe the OR of the complications (Figure 2). Secondly, we built a model for each of our objectives to study the association of uncontrolled risk factors in suboptimal glycaemic control. Model 1 included only sex and SES index as fixed effects. In model 2, younger age, longer time from diagnosis, having ischaemic heart disease, peripheral arteriopathy, diabetic retinopathy and being in SES quintile 4 and 5 explained suboptimal glycaemic control; sex was not associated with glycaemic control.

Once we studied the combined control targets (models 3 and 4), we found that being female was more likely to unachieve the combined targets along with belonging to SES quintile 4 and 5, peripheral arteriopathy and diabetic retinopathy. Models with every single target can be checked in Additional file 6 , uncontrolled BP (OR: 1.22, IC:1.17-1.27) and obesity (OR: 1.19, IC: 1.14-1.24) are more related to uncontrolled glycaemic target.

\section{Discussion}

\section{Key results}

The glycaemic control was achieved by $63 \%$ of primary care diabetic patients aged $40-75$ years. Combined controlled targets (HbA1c, BP and LDL), that percentage fall down to $10 \%$ and in case we added the $\mathrm{BMl}<30 \mathrm{~kg} / \mathrm{m}^{2}$, it decreased to $6.6 \%$. Women had better glycaemic control (HbA1c) but worst combined targets regardless of the SES index.

Sex was not related with suboptimal glycaemic control when adjusted by covariables but being part of SES quintile 4 and 5 was associated with not reaching the glycaemic goal. When the combined target was analysed being female was related to suboptimal control regardless the SES index and comorbities. Cumulative disadvantage can be seen in women less affluent as they suffer more obesity and hypertension.

\section{Comparison with other studies}

In our population, we found that $60.5 \%$ of our patients had had their HbA1 checked in the last year. One study in Canada reported that there were $68.9 \%$ of patients with a baseline HbA1c assessment at a one-year follow-up (43). However, a study in UK measured the impact of a quality care programme for T2D during 5 years, they started measuring $\mathrm{HbA} 1 \mathrm{c}$ in $82.5 \%$ of their population in one-year follow-up but they raised this percentage to $99.6 \%$ at the end of the study. In their case, only $69 \%$ had all the annual measures during the 5 years (20). In our study, high-SES participants were less likely to have an HbA1c measure, which could be explained by patients in that quintile being able to afford private insurance. This contrasts with the UK study where patients belonging to the SES quintile 5 were more likely not to have annual $\mathrm{HbA} 1 \mathrm{c}$ monitoring.

Our patients reached the glycaemic target in 63.2\%, this finding is concordant to other studies in Spain where patients reached it over 55-60.1\% (16,18). Optimal glycaemic target has been described in $62.8 \%$ of patients in Norway (44), $52.9 \%$ in Canada (14), and $46.7 \%$ of patients in the UK (20). A different approach would be to consider optimal glycaemic control if HbA1c was $\leq 8.5 \mathrm{mg} / \mathrm{dl}$, a study in the US found optimal control in $64 \%$ of their patients (45) and in our study it would be $90.4 \%$. It is complicated to compare these percentages when health care access differs so much among countries. By taking into account a global perspective of the disease, we found that sex and SES were related to the achievement of targets. The effect of sex on glycaemic control has been discussed before without clear findings. Some studies suggested that women were more likely to have suboptimal control $(18,19)$ but other studies found the opposite $(15,16)$. Even so, these differences were less than $2 \%$ between men and women. In our study, women reached more glycaemic goal than men $(64,2 \%$ vs $62,4 \%)$ but sex was not related to optimal glycaemic control while SES index did. The optimal control decreased in both sexes from the quintile 1 to quintile 5 , being on quintile 4 and 5 related to not achieving glycaemic goal. Our results are according to Collier et al (19) and Whyte et al (20), both studies showed how being more deprived was less likely to reach the glycaemic target. These results show that T2D approach should also address social inequalities to try to improve the glycaemic target in those patients more disadvantaged.

Page $4 / 11$ 
Our study evaluated optimal combined control of T2D, compared with Wan et al., who found an optimal combined control in $9.45 \%$ of their patients, our result of $10 \%$ optimal combined control was similar. However, Braga et al described that $19 \%$ of their patients met the three goals (14); that difference is due to doctors who enrolled patients that were given recommendations to follow carefully the guidelines. In Spain, Ibáñez et al. published that patients with a lower SES less frequently reached HbA1c and BP targets, which corresponds with our results (18). However, in our case, patients who achieved the combined target more frequently were those in quintile 5 , which could be explained by patients in the quintile 5 visiting their primary care centers more, because of their complications, that those in quintile 1 and 2. Patients in quintile 1 and 2 also could have doctors in secondary care so they received less holistic and longitudinal care. We did not find any study that added BMl<30 kg/m to the combined variable; however, we decided to include it because obesity is linked to T2D (46) and to belong to the more deprived quintiles (19), when adding this risk factor a quite poor result appeared, only $6,6 \%$ achieved the four targets.

These findings highlight the need for questioning which goals we are chasing when we address T2D. In this study, we focused on the factors that collaborate in not achieving an optimal glycaemic control. We found a positive association between these factors and being female, more deprived and suffering of peripheral arteriopathy or retinopathy. Turning to other studies, Wan et al set the goal in reducing cardiovascular risk, they studied the combined target and suggested that reducing LDL should be the main goal when we failed to achieve them all. In our case, we found we should be prioritizing BP and weight control to achieve glycaemic control. Rodríguez-Gutiérrez et al reviewed the impact of tight glycaemic control in complications and mortality (47). They did not find a benefit on the risk of complications except for a $15 \%$ relative-risk reduction of nonfatal myocardial infarction. We should start seeing T2D as a complex disease where research should not address only one target but all of them. Achieving the four targets in our study has been shown unrealistic based on our data. That is the reason why we found how improving BP and BMI control could improve the glycaemic control. We need more data with this approach to understand which targets are more beneficial for the patients. On the other hand, SES perspective should also be taken into account. If we address T2D as an illness where cumulative disadvantage is present $(48,49)$, we will focus in those groups of patients who are more vulnerable.

Our results of cardiovascular complications were similar to those observed in the Penno et al (22) and Tecos cohort (23), where men had more cardiovascular events. This finding could be explained by the use of tobacco ( $21.9 \%$ for men versus $13 \%$ for women). However, our study contrasts with Peno and Tecos research $(19,20)$ about microvascular complications; we found that men had more retinopathy and chronic renal disease, whereas the previous studies observed these complications more frequently in female patients. We reviewed the situation of the chronic kidney disease (CKD) where male have a higher prevalence of the illness, there are a few studies which have similar results to us $(32,50,51)$. They pointed out age, systolic BP, smoking and high albuminuria as risk factors for a decline in the glomerular rate. In our case, men had higher albuminuria and use of tobacco which might explain our results. On the other hand, a meta-analysis (52) revealed the relationship between lower SES and CKD, which is in accordance with our results. About the other microvascular complications, we used EHR to obtain the result of the retinopathy (DR). Most patients are screened and followed in secondary care. This situation could explain that our prevalence is lower than other studies $(53,54)$. A study found that being male and having uncontrolled BP, DM2, BMI and smoking was related to have retinopathy(55), our results are parallel to them.

A meta-analysis conducted by Peters et al. described a higher relative risk of stroke for women with T2D (women: RR: 2.28 (95\% Cl 1.93-2.69), men: RR: 1.83 (1.60-2.08) (29). In our study, women had fewer episodes of stroke, which is consistent with a local study (56), where women also had more hypertension and were less likely to smoke. Another point to explain this result relates to age; our population was between 40-75 years old, whereas women have more ischaemic stroke in the age interval of 55-74 years (57), which could also explain these differences. In this study, ischaemic heart disease was more frequent in men and especially in those in quintile. 1 In contrast, Collier et al. showed that men in quintile 5 had a higher prevalence of ischaemic heart disease (19). Our results are similar to Collier that those men in the last quintile were more likely to be smokers and had more peripheral arteriopathy than men on the first quintile. When we analysed women, those in quintile 5 had a higher prevalence of obesity, hypertension and nearly all complications except for peripheral arteriopathy. Nevertheless, women in quintiles 1 and 2 smoked more than women in the last quintiles. Peripheral arteriopathy was found in the last quintiles by Collier et al. In this sense, smoking could be the cause of this difference.

\section{Strengths and limitations}

The main strength of this study was to describe the whole T2D population of Madrid city through real-world data from the EHR. The study was limited by the use of private health of some patients in quintiles 1 and 2, so the record in those quintiles could be less accurate. Additionally, some patients were followed at secondary care facilities, and not all records were available in the primary care EHRs. In our data, we did not have the lifestyle record, treatment of the patients or number of primary care visits; those variables could have helped us to interpret our results more clearly. Lastly, we have missing data from some of the variables which were excluded from the analysis. We provided the number of patients of each group in table 1 but we cannot exclude the possibility of bias because of the missing data.

\section{Implications for practice and research}

Our study showed the difficulty in managing T2D as a global disease with multiple targets even among those living in a country with a national public health system. More studies are needed to address T2D as a multitarget disease. Research should be focused in explaining which targets should be prioritized when we are failing to achieve them all. These findings highlight that a minority of patients could achieve all the targets, future studies should explain which factors contribute to reach them and how to take into account those factors in the approach of the disease. But we lighted that sex and SES may have a role in optimal control of diabetes and cardiovascular risk factors. Social determinants, such as the SES index, should be included in the T2D studies and guidelines to improve the quality of care particularly for those who are most disadvantaged. Doctors should be trained to address social determinants as they are trained to treat T2D but also public policies should include take them in account to reduce social inequalities.

\section{Conclusions}


This study showed that disparity in glycaemic and combined control were related to being less affluent in SES and having ischaemic heart disease, peripheral arteriopathy or retinopathy. Differences in glycaemic control and other areas of care (control of hypertension, dyslipidaemia, obesity and tobacco use) may lead to higher rates of complications for some groups of type 2 diabetic patients. Optimal combined control target $(\mathrm{HbA} 1 \mathrm{c} \leq 7 \%$, LDL $<100 \mathrm{mg} / \mathrm{dl}$, and $\mathrm{BP}<140 / 90 \mathrm{~mm} \mathrm{Hg}$ ) was seldom achieved, men and patients in quintile 5 were the ones who achieved it most.

\section{List Of Abbreviations}

T2D, type 2 diabetes mellitus. SES, socioeconomic status. EHR, electronic health record. BMI, body mass index. DI. BP: blood pressure. SBP: systolic blood pressure. DBP: diastolic blood pressure. PHC: primary health centre. UK: United Kingdom. US: United States of America.

\section{Declarations}

Ethics approval and consent to participate: The HHH global study was approved by Madrid Primary Care Research Committee and the Ethics in Research Committee of the Madrid Health Care System (ERC-2013-StG-336893). This work was additionally approved by the Ethics in Research Committee of the Ramón y Cajal Hospital at Madrid city (341/2018).

Consent for publication: Not Applicable.

Availability of data and materials: All data generated or analysed during this study are included in this published article [and its Additional files information files]. All methods were carried out in accordance with relevant guidelines and regulations.

Competing interests: The authors declare that they have no competing interests.

Funding: The Heart Healthy Hoods project was funded by the European Research Council under the European Union's Seventh Framework Programme (FP7/2007-2013/ERC Starting Grant Heart Healthy Hoods Agreement n. 336893). SA has received a grant from the Foundation for Biomedical Research and Innovation in Primary Care (FIIBAP) for translation and publication in its 2019 call. SA received funding from the Spanish Society of Family and Community Medicine -semFYC- as it won a grant for the completion of doctoral theses Isabel Fernández 2018.

Authors' contributions: SA, EP, IC contributed to conception and design, participated in acquisition of data, analysed and interpreted data, drafted the manuscript, revised the manuscript critically for important intellectual content, and provided final approval of the version to be published. FR, LS participated in acquisition of data, analysed and interpreted data revised the manuscript and provided final approval of the version to be published. PG, MF revised the manuscript for important intellectual content, and provided final approval of the version to be published. All authors read and approved the final manuscript.

Acknowledgements: Sarah Collen and Jairo Ares provided professional writing services.

\section{Bibliography}

1. Federation ID. Diabetes Atlas Ninth edition 2019 [Internet]. 2019. Available from: https://diabetesatlas.org/upload/resources/material/20200302_133351_IDFATLAS9e-final-web.pdf

2. Fuller D, Neudorf J, Lockhart S, Plante C, Roberts H, Bandara T, et al. Individual- and area-level socioeconomic inequalities in diabetes mellitus in Saskatchewan between 2007 and 2012: a cross-sectional analysis. C Open. 2019;7(1):E33-9.

3. Tancredi M, Rosengren A, Svensson A-M, Kosiborod M, Pivodic A, Gudbjörnsdottir S, et al. Excess Mortality among Persons with Type 2 Diabetes. N Engl J Med [Internet]. 2015;373(18):1720-32. Available from: http://www.nejm.org/doi/10.1056/NEJMoa1504347

4. Roche MM, Wang PP. Sex differences in all-cause and cardiovascular mortality, hospitalization for individuals with and without diabetes, and patients with diabetes diagnosed early and late. Diabetes Care. 2013;36(9):2582-90.

5. American Diabetes Association. Standards of medical care in diabetes 2020. Diabetes Care [Internet]. 2020;43(SUPPL. 1). Available from: https://care.diabetesjournals.org/content/diacare/suppl/2019/12/20/43.Additional file_1.DC1/Standards_of_Care_2020.pdf

6. NICE guidelines. Type 2 diabetes in adults: management. 2018;1-44.

7. Blonde L, Aschner P, Bailey C, Ji L, Leiter LA, Matthaei S. Gaps and barriers in the control of blood glucose in people with type 2 diabetes. Diabetes Vasc Dis Res. 2017;14(3):172-83.

8. Arrieta F, Piñera M, Iglesias P, Nogales P, Salinero-Fort MA, Abanades JC, et al. Metabolic control and chronic complications during a 3-year follow-up period in a cohort of type 2 diabetic patients attended in primary care in the Community of Madrid (Spain). Endocrinol y Nutr. 2014;61(1):11-7.

9. Edelman S V., Polonsky WH. Type 2 diabetes in the real world: The elusive nature of glycemic control. Diabetes Care. 2018;41(2):e18.

10. Wan EYF, Yu EYT, Fung CSC, Chin WY, Fong DYT, Chan AKC, et al. Relation between HbA1cand incident cardiovascular disease over a period of 6 years in the Hong Kong population. Diabetes Metab. 2018;1-9.

11. Larrañaga I, Arteagoitia JM, Rodriguez JL, Gonzalez F, Esnaola S, Piniés J a. Socio-economic inequalities in the prevalence of Type 2 diabetes, cardiovascular risk factors and chronic diabetic complications in the Basque Country, Spain. Diabet Med. 2005;22(8):1047-53.

12. Wolters RJJ, Braspenning JCCCC, Wensing M. Impact of primary care on hospital admission rates for diabetes patients: A systematic review. Diabetes Res Clin Pract [Internet]. 2017;129:182-96. Available from: http://dx.doi.org/10.1016/j.diabres.2017.05.001

13. Cavero-Redondo I, Peleteiro B, Álvarez-Bueno C, Rodriguez-Artalejo F, Martínez-Vizcaíno V. Glycated haemoglobin A1c as a risk factor of cardiovascular outcomes and all-cause mortality in diabetic and non-diabetic populations: a systematic review and meta-analysis. BMJ Open [Internet].

Page 6/11 
2017;7(7):e015949. Available from: http://bmjopen.bmj.com/lookup/doi/10.1136/bmjopen-2017-015949

14. Braga MFB, Casanova A, Teoh H, Gerstein HC, Fitchett DH, Honos G, et al. Poor achievement of guidelines-recommended targets in type 2 diabetes: Findings from a contemporary prospective cohort study. Int J Clin Pract. 2012;66(5):457-64.

15. Ji L, Hu D, Pan C, Weng J, Huo Y, Ma C, et al. Primacy of the 3B approach to control risk factors for cardiovascular disease in type 2 diabetes patients. Am J Med. 2013;126(10):925.e11-925.e22.

16. Franch-nadal J, Mata-cases M, Vinagre I, Patitucci F, Hermosilla E, Casellas A, et al. Differences in the Cardiometabolic Control in Type 2 Diabetes according to Gender and the Presence of Cardiovascular Disease: Results from the eControl Study. Int J Endocrinol. 2014;131709:11.

17. Wan EYF, Fung CSC, Yu EYT, Chin WY, Fong DYT, Chan AKC, et al. Effect of multifactorial treatment targets and relative importance of hemoglobin A1C, blood pressure, and low-density lipoprotein-cholesterol on cardiovascular diseases in Chinese primary care patients with type 2 diabetes mellitus: $\mathrm{A}$ population-based ret. J Am Heart Assoc. 2017;6(8).

18. Ibáñez B, Galbete A, Goñi MJ, Forga L, Arnedo L, Aizpuru F, et al. Socioeconomic inequalities in cardiometabolic control in patients with type 2 diabetes. BMC Public Health [Internet]. 2018 Dec 27;18(1):408. Available from: https://bmcpublichealth.biomedcentral.com/articles/10.1186/s12889-018-5269-0

19. Collier A, Ghosh S, Hair M, Waugh N. Impact of socioeconomic status and gender on glycaemic control, cardiovascular risk factors and diabetes complications in type 1 and 2 diabetes: A population based analysis from a Scottish region. Diabetes Metab [Internet]. 2015;41(2):145-51. Available from: http://dx.doi.org/10.1016/j.diabet.2014.09.004

20. Whyte MB, Hinton W, McGovern A, Van Vlymen J, Ferreira F, Calderara S, et al. Disparities in glycaemic control, monitoring, and treatment of type 2 diabetes in England: A retrospective cohort analysis. PLoS Med. 2019;16(10):1-18.

21. Wan EYF, Fung CSC, Yu EYT, Chin WY, Fong DYT, Chan AKC, et al. Effect of multifactorial treatment targets and relative importance of hemoglobin A1C, blood pressure, and low-density lipoprotein-cholesterol on cardiovascular diseases in Chinese primary care patients with type 2 diabetes mellitus: $\mathrm{A}$ population-based ret. J Am Heart Assoc. 2017;6(8).

22. Penno G, Solini A, Bonora E, Fondelli C, Orsi E, Zerbini G, et al. Gender differences in cardiovascular disease risk factors, treatments and complications in patients with type 2 diabetes: The RIACE Italian multicentre study. J Intern Med. 2013;274(2):176-91.

23. Alfredsson J, Green JB, Stevens SR, Reed SD, Armstrong PW, Angelyn Bethel M, et al. Sex differences in management and outcomes of patients with type 2 diabetes and cardiovascular disease: A report from TECOS. Diabetes, Obes Metab. 2018;20(10):2379-88.

24. Mulnier HE, Seaman HE, Raleigh VS, Soedamah-Muthu SS, Colhoun HM, Lawrenson RA, et al. Risk of myocardial infarction in men and women with type 2 diabetes in the UK: A cohort study using the General Practice Research Database. Diabetologia. 2008;51(9):1639-45.

25. Dong X, Cai R, Sun J, Huang R, Wang P, Sun H, et al. Diabetes as a risk factor for acute coronary syndrome in women compared with men: a metaanalysis, including 10856279 individuals and 106703 acute coronary syndrome events. Diabetes Metab Res Rev. 2017;33(5a).

26. Gao F, Lam CSP, Sim LL, Koh TH, Foo D, Ong HY, et al. Impact of the joint association between sex, age and diabetes on long-term mortality after acute myocardial infarction. BMC Public Health [Internet]. 2015;15(1):308. Available from: http://bmcpublichealth.biomedcentral.com/articles/10.1186/s12889015-1612-x

27. Gouni-Berthold I, Berthold HK, Mantzoros CS, Böhm M, Krone W. Sex disparities in the treatment and control of cardiovascular risk factors in type 2 diabetes. Diabetes Care [Internet]. 2008;31(7):1389. Available from: http://care.diabetesjournals.org/content/31/7/1389.short

28. Grupo Barbanza para el Estudio de las Enfermedades Cardiovasculares. [Characteristics of the patients with heart disease in a health area of A Coruña province. Barbanza 2000 study]. Rev clínica española [Internet]. 2003 Dec;203(12):570-6. Available from:

http://www.ncbi.nlm.nih.gov/pubmed/14622505

29. Peters SAE, Huxley RR, Woodward M. Diabetes as a risk factor for stroke in women compared with men: A systematic review and meta-analysis of 64 cohorts, including 775385 individuals and 12539 strokes. Lancet [Internet]. 2014;383(9933):1973-80. Available from: http://dx.doi.org/10.1016/S01406736(14)60040-4

30. Amin L, Shah BR, Bierman AS, Lipscombe LL, Wu CF, Feig DS, et al. Gender differences in the impact of poverty on health: Disparities in risk of diabetesrelated amputation. Diabet Med. 2014;31(11):1410-7.

31. Peek ME. Gender differences in diabetes-related lower extremity amputations. Clin Orthop Relat Res. 2011;469(7):1951-5.

32. Teliti M, Cogni G, Sacchi L, Dagliati A, Marini S, Tibollo V, et al. Risk factors for the development of micro-vascular complications of type 2 diabetes in a single-centre cohort of patients. Diabetes Vasc Dis Res. 2018;15(5):424-32.

33. Goderis G, Van Pottelbergh G, Truyers C, Van Casteren V, De Clercq E, Van Den Broeke C, et al. Long-term evolution of renal function in patients with type 2 diabetes mellitus: a registry-based retrospective cohort study. BMJ Open [Internet]. 2013;3(12):e004029. Available from: http://www.pubmedcentral.nih.gov/articlerender.fcgi?artid=3884754\&tool=pmcentrez\&rendertype=abstract

34. Nielsen ABS, De Fine Olivarius N, Gannik D, Hindsberger C, Hollnagel H. Structured personal diabetes care in primary health care affects only women's HbA1c. Diabetes Care. 2006;29(5):963-9.

35. Yu MK, Lyles CR, Bent-Shaw LA, Young BA. Sex disparities in diabetes process of care measures and self-care in high-risk patients. J Diabetes Res. 2013;2013

36. Ozawa GY, Bearse MA, Adams AJ. Male-female differences in diabetic retinopathy? Curr Eye Res. 2015;40(2):234-46.

37. Tracey ML, McHugh SM, Fitzgerald AP, Buckley CM, Canavan RJ, Kearney PM. Risk Factors for Macro- and Microvascular Complications among Older Adults with Diagnosed Type 2 Diabetes: Findings from The Irish Longitudinal Study on Ageing. J Diabetes Res [Internet]. 2016;2016(Cvd):1-9. Available from: http://www.hindawi.com/journals/jdr/2016/5975903/ 
38. Aguilar-Palacio I, Martinez-Beneito MA, Rabanaque MJ, Borrell C, Cirera L, Daponte A, et al. Diabetes mellitus mortality in Spanish cities: Trends and geographical inequalities. Prim Care Diabetes [Internet]. 2017 Jun 13;1-8. Available from: http://www.ncbi.nlm.nih.gov/pubmed/28623082

39. Mayero L. Sanidad privada, análisis de situación 2019. Inst para el Desarro e Integr la Sanid [Internet]. 2019;7-16. Available from: https://www.fundacionidis.com/informes/analisis-de-situacion-de-la-sanidad-privada/sanidad-privada-aportando-valor-analisis-de-situacion-2019

40. de Burgos-Lunar C, Salinero-Fort MA, Cárdenas-Valladolid J, Soto-Díaz S, Fuentes-Rodríguez CY, Abánades-Herranz JC, et al. Validation of diabetes mellitus and hypertension diagnosis in computerized medical records in primary health care. BMC Med Res Methodol [Internet]. 2011;11(1):146. Available from: https://www.ncbi.nlm.nih.gov/pmc/articles/PMC3215645/pdf/1471-2288-11-146.pdf\%5Cnhttps://www.scopus.com/inward/record.uri?eid=2-s2.080054995048\&doi=10.1186\%2F1471-2288-11-146\&partnerID=40\&md5=805d6c4bf288f336f356c403faa7a499

41. Bilal U, Díez J, Alfayate S, Gullón P, Del Cura I, Escobar F, et al. Population cardiovascular health and urban environments: The Heart Healthy Hoods exploratory study in Madrid, Spain. BMC Med Res Methodol [Internet]. 2016;16(1):1-12. Available from: http://dx.doi.org/10.1186/s12874-016-0213-4

42. Domínguez-Berjón MF, Borrell C, Cano-Serral G, Esnaola S, Nolasco A, Pasarín MI, et al. [Constructing a deprivation index based on census data in large Spanish cities(the MEDEA project)]. Gac Sanit [Internet]. 2008;22(3):179-87. Available from: http://www.ncbi.nlm.nih.gov/pubmed/18579042

43. Campitelli MA, Kumar M, Greenberg A. Integrating Population-Wide Laboratory Testing Data with Audit and Feedback Reports for Ontario Physicians. Healthc Q. 2018;21(2):6-9.

44. Bakke Å, Cooper JG, Thue G, Skeie S, Carlsen S, Dalen I, et al. Type 2 diabetes in general practice in Norway 2005 - 2014 : moderate improvements in risk factor control but still major gaps in complication screening. BMJ Open Diab Res Care. 2017;5(e000459).

45. Kazemian P, Shebl FM, McCann N, Walensky RP, Wexler DJ. Evaluation of the Cascade of Diabetes Care in the United States, 2005-2016. JAMA Intern Med. 2019;179(10):1376-85.

46. Calsbeek H, Markhorst JGM, Voerman GE. Case-Mix Adjustment for Diabetes Indicators: Am J Manag Care. 2016;22(2).

47. Rodríguez-Gutiérrez R, Montori VM. Glycemic control for patients with type 2 diabetes mellitus: Our evolving faith in the face of evidence. Circ Cardiovasc Qual Outcomes. 2016;9(5):504-12.

48. Backholer K, Peters SAE, Bots SH, Peeters A, Huxley RR, Woodward M. Sex differences in the relationship between socioeconomic status and cardiovascular disease: A systematic review and meta-analysis. J Epidemiol Community Health. 2017;71(6):550-7.

49. Gagné T, Veenstra G. Inequalities in Hypertension and Diabetes in Canada: Intersections between Racial Identity, Gender, and Income. Ethn Dis [Internet]. 2017 Dec 7;27(4):371. Available from: https://www.ethndis.org/edonline/index.php/ethndis/article/view/727

50. de Hauteclocque A, Ragot S, Slaoui Y, Gand E, Miot A, Sosner P, et al. The influence of sex on renal function decline in people with Type 2 diabetes. Diabet Med. 2014;31(9):1121-8.

51. Meguro S, Tomita M, Kabeya Y, Katsuki T, Oikawa Y, Shimada A, et al. Factors associated with the decline of kidney function differ among eGFR strata in subjects with type 2 diabetes mellitus. Int J Endocrinol. 2012;2012.

52. Vart P, Gansevoort RT, Joosten MM, Bültmann U, Reijneveld SA. Socioeconomic disparities in chronic kidney disease: A systematic review and metaanalysis. Am J Prev Med [Internet]. 2015;48(5):580-92. Available from: http://dx.doi.org/10.1016/j.amepre.2014.11.004

53. Rodríguez-Poncelas A, Mundet-Tudurí X, Miravet-Jiménez S, Casellas A, Barrot-De La Puente JF, Franch-Nadal J, et al. Chronic Kidney Disease and Diabetic Retinopathy in Patients with Type 2 Diabetes. PLoS One. 2016;11(2):1-10.

54. Denniston AK, Lee AY, Lee CS, Crabb DP, Bailey C, Lip PL, et al. United Kingdom Diabetic Retinopathy Electronic Medical Record (UK DR EMR) Users Group: Report 4, real-world data on the impact of deprivation on the presentation of diabetic eye disease at hospital services. Br J Ophthalmol. 2018;(Imd):83743.

55. Hammes HP, Welp R, Kempe HP, Wagner C, Siegel E, Holl RW. Risk factors for retinopathy and DME in type 2 diabetes-results from the German/Austrian DPV database. PLoS One. 2015;10(7):4-13.

56. Munoz-Rivas N, Mendez-Bailon M, Hernandez-Barrera V, De Miguel-Yanes JM, Jimenez-Garcia R, Esteban-Hernandez J, et al. Time trends in ischemic stroke among type 2 diabetic and non-diabetic patients: Analysis of the Spanish national hospital discharge data (2003-2012). PLoS One. 2015;10(12):117.

57. Policardo L, Seghieri G, Francesconi P, Anichini R, Franconi F, Del Prato S. Gender difference in diabetes related excess risk of cardiovascular events: When does the 'risk window' open? J Diabetes Complications [Internet]. 2017;31(1):74-9. Available from: http://dx.doi.org/10.1016/j.jdiacomp.2016.09.010

\section{Tables}

Table 1: General characteristics of population and characteristics by unachieved targets. 


\begin{tabular}{|c|c|c|c|c|c|c|c|c|c|}
\hline \multirow{2}{*}{$\begin{array}{l}\text { Patient characteristics: } \\
\text { N }\end{array}$} & \multirow{2}{*}{$\begin{array}{l}\text { Patients } \\
\text { with } \\
\text { HbA1c } \\
\text { tested } \\
\\
68535\end{array}$} & $\begin{array}{l}\text { Patients } \\
\text { with } \\
\text { HbA1>7\% }\end{array}$ & \multicolumn{2}{|c|}{$\begin{array}{l}\text { Patients with } \\
\text { BP }>140 / 90 \\
\text { Mm Hg }\end{array}$} & $\begin{array}{l}\text { Patients with } \\
\text { LDL>100 } \\
\mathrm{mg} / \mathrm{dl}\end{array}$ & $\begin{array}{l}\text { Patients with } \\
\mathrm{BMl}>30 \\
\mathrm{~kg} / \mathrm{m} 2\end{array}$ & \multicolumn{2}{|c|}{$\begin{array}{l}\text { Uncontrolled } \\
\text { combined target: } \\
\mathrm{HbA} 1 \mathrm{c}, \mathrm{BP}, \mathrm{LDL}\end{array}$} & \multirow{2}{*}{$\begin{array}{l}\text { Uncontrı } \\
\text { target: } \\
\text { HbA1c, I } \\
\end{array}$} \\
\hline & & \multicolumn{2}{|c|}{25239} & \multicolumn{2}{|c|}{18700} & 16871 & 18407 & 44507 & \\
\hline Mean age * & $62.7(8.8)$ & \multicolumn{2}{|c|}{$61.8(9.1)$} & \multicolumn{2}{|c|}{$64.3(8.4)$} & $61.3(9.0)$ & $62.3(8.9)$ & \multicolumn{2}{|c|}{$62.5(8.9)$} \\
\hline Evolution of T2D (years)* & $9.40(6.0)$ & \multicolumn{2}{|c|}{$10.9(6.3)$} & \multicolumn{2}{|c|}{$9.9(6.2)$} & $8.2(5.7)$ & $9.2(6.0)$ & \multicolumn{2}{|c|}{$9.8(6.2)$} \\
\hline Foreigners ** & $4111(6.0)$ & \multicolumn{2}{|c|}{$1041(6.8)$} & \multicolumn{2}{|c|}{$920(4.9)$} & $1290(7.6)$ & $993(5.4)$ & \multicolumn{2}{|c|}{$2925(6.6)$} \\
\hline Men** & $38955(56.8)$ & \multicolumn{2}{|c|}{$14648(58.04)$} & \multicolumn{2}{|c|}{$10101(54.0)$} & $8557(50.7)$ & 9405 (51.1) & \multicolumn{2}{|c|}{$24665(55.4)$} \\
\hline Women** & $29580(43.2)$ & 1059 & $1(41.9)$ & 859 & 46.0) & $8314(49.3)$ & $9002(48.9)$ & 198 & $(44.6))$ \\
\hline $\begin{array}{l}\text { Socioeconomic status } \\
\text { index*: }\end{array}$ & & & & & & & & & \\
\hline 1, least deprived & $14764(21.6)$ & 5033 & $(20.0)$ & 374 & 20.1) & $3941(23.5)$ & 3458 (18.9) & 927 & 20.9) \\
\hline 2 & 12405 (18.2) & 4363 & (17.3) & 348 & 18.7) & $3927(23.5)$ & $3200(17.4)$ & 846 & 19.1) \\
\hline 3 & $13110(19.2)$ & 4722 & (18.8) & 373 & 20.1) & 3039(18.1)) & $3345(18.2)$ & 841 & 19.0) \\
\hline 4 & $15393(22.6)$ & 5966 & (23.7) & 419 & 22.5) & $2311(13.8)$ & $4566(24.9)$ & 947 & 21.4) \\
\hline 5, more deprived & $12568(18.4)$ & 5065 & $(20.1)$ & 346 & (18.6) & $3526(21.1)$ & $3775(20.6)$ & 867 & 19.6) \\
\hline Cardiovascular Risk Facto & & & & & & & & & \\
\hline Tobacco & 4799 (18.0) & 1889 & (18.9) & 172 & $(17.1)$ & 1265(19.2) & $1602(15.7)$ & 337 & 18.0) \\
\hline Dyslipidaemia & $43135(62.9)$ & 1571 & $5(62.3)$ & 120 & $(64.2)$ & $10526(62.4)$ & $11672(63.4)$ & 280 & $(63.0)$ \\
\hline Hypertension & $25400(37.1)$ & 9524 & (37.7) & 372 & 19.9) & $9933(58.9)$ & $6735(36.6)$ & 154 & (34.6) \\
\hline Clinical Parameters*: & & & & & & & & & \\
\hline $\mathrm{SBP}(\mathrm{mmHg})$ & $139.5(16.9)$ & 140 & (17.5) & 155 & $(13.1)$ & $139.9(17.3)$ & $141.9(16.7)$ & 143 & (17.5) \\
\hline DBP $(\mathrm{mmHg})$ & $80.4(10.0)$ & 80.7 & (10.3) & 86.4 & $(10-0)$ & $81.6(10.1)$ & $82.5(10.0)$ & 82.2 & $0.3)$ \\
\hline BMI (kg/m2) & $30.2(5.2)$ & 30.4 & $(5.4)$ & 30.8 & 5.4) & $30.1(5.3)$ & $34.5(4.1)$ & 30. & .3) \\
\hline HbA1c (\%) & $6.9(1.2)$ & $8.1(1$ & & 7.0( & & $7.0(1.3)$ & $7.05(1.2)$ & 7.3 & \\
\hline $\mathrm{LDL}(\mathrm{mg} / \mathrm{dL})$ & $103.2(32.7)$ & 103. & $(34.1)$ & $(30$. & 99.7 & $129.1(24.0)$ & $102.1(32.2)$ & 111 & (32.7) \\
\hline $\begin{array}{l}\text { eGFR, } \\
(\mathrm{mL} / \mathrm{min} / 1,73 \mathrm{~m} 2)\end{array}$ & 82.1(17.1) & 81.9 & (17.8) & $(17.2$ & 80.8 & $82.5(16.4)$ & $81.4(17.6)$ & 81.8 & 7.2) \\
\hline Albuminuria (mg/g) & $48.9(310.3)$ & 63.3 & $(424.6)$ & 72.4 & 01.4) & $45.9(217.4)$ & $50.5(226.8)$ & 56.6 & 363.0) \\
\hline T2D Complications**: & & & & & & & & & \\
\hline Coronary heart disease & 7057 (10.3) & 2830 & $(11.2)$ & 180 & (9.6) & 649 (3.8) & $1830(9.9)$ & 410 & 9.2) \\
\hline Stroke & $3908(5.7)$ & 1482 & $(5.9)$ & 118 & (6.3) & $599(3.6)$ & $1047(5.7)$ & 243 & $5.5)$ \\
\hline Peripheral Arteriopathy & $3212(4.7)$ & 1394 & $(5.5)$ & 102 & (5.5) & $520(3.1)$ & $837(4.5)$ & 214 & 4.8) \\
\hline Renal Chronic Disease & $6,613(15.1)$ & 2,524 & $(16.6)$ & 716 & & $323(1.9)$ & $1,933(16.2)$ & 4,57 & $(16.0)$ \\
\hline Diabetic Nephropathy & $2.232(14.4)$ & 1,073 & (19.4) & 827 & 8.5) & $480(13.2)$ & $698(15.9)$ & 1,63 & (16.4) \\
\hline Retinopathy & $2127(3.1)$ & 1229 & (4.9) & 723 & & $339(2.0)$ & $595(3.2)$ & 159 & 3.6) \\
\hline
\end{tabular}

SBP: systolic blood pressure. DBP: diastolic blood pressure, BMI: body mass index. eGFR: Estimated glomerular filtration rate

Targets of optimal combined control, patients had to achieve all the targets: $\mathrm{HbA} 1 \mathrm{c} \leq 7 \%, \mathrm{BP}<140 / 90 \mathrm{~mm} \mathrm{Hg}, \mathrm{LDL}<100 \mathrm{mg} / \mathrm{dl}$ and BMl $<30 \mathrm{~kg} / \mathrm{m}^{2}$. *: $\mathrm{mean}$ (sd) **: $n(\%$

Table 2: Adjusted ORs for the effect of sex and SES index on suboptimal glycaemic control 


\begin{tabular}{lcccc}
\hline Model 1: Glycaemic control & Model 2: Glycaemic control \\
OR (95\% CI) & OR (95\% CI) & $\begin{array}{c}\text { Model 3: Combined } \\
\text { control target } \\
\text { (HbaA1c, BP, LDL) } \\
\text { OR (95\% CI) }\end{array}$ & $\begin{array}{c}\text { Model 4: Combined } \\
\text { control target (HbaA1c, BP, } \\
\text { LDL \& BMI) } \\
\text { OR (95\% CI) }\end{array}$ \\
\hline Sex (male) & & & \\
\hline
\end{tabular}

Socioeconomic Status index

(1: least deprived, reference)

\begin{tabular}{lcccc}
\hline 2 & $1.02(0.93-1.11)$ & $0.98(0.90-1.07)$ & $0.79(0.58-1.08)$ & $0.75(0.51-1.10)$ \\
\hline 3 & $1.06(0.96-1.16)$ & $1.01(0.92-1.11)$ & $0.83(0.59-1.16)$ & $0.83(0.54-1.27)$ \\
\hline 4 & $1.23(1.13-1.35)$ & $1.16(1.06-1.26)$ & $1.47(1.04-2.07)$ & $1.41(0.92-2.15)$ \\
\hline 5 & $1.30(1-18-1.42)$ & $1.20(1.10-1.32)$ & $1.09(0.77-1.54)$ & $1.11(0.72-1.70)$ \\
\hline Age & & $0.96(0.96-0.97)$ & $0.96(0.96-0.97)$ & $0.96(0.96-0.97)$ \\
\hline Evolution of T2D & $1.08(1.08-1.09)$ & $1.01(1.00-1.02)$ & $1.00(0.99-1.00)$ \\
\hline Coronary heart disease & & $1.10(1.04-1.16)$ & $0.56(0.52-0.62)$ & $0.66(0.59-0.75)$ \\
\hline Peripheral Arteriopathy & & $1.22(1.13-1.32)$ & $1.01(0.88-1.16)$ & $1.11(0.92-1.35)$ \\
\hline Diabetic Retinopathy & & $1.68(1.53-1.84)$ & $1.44(1.18-1.75)$ & $1.18(0.91-1.52)$ \\
\hline AIC /BIC & $93816 / 93889$ & $90060 / 90179$ & $20522 / 20636$ & $1013 / 1123$ \\
\hline Variance of the constant & 0.001 & 0.0008 & 0.003 & 0.001 \\
\hline Residual variance & $0.23(0.22-0.23)$ & $0.21(0.21-0.22)$ & $0.08(0.08-0.089)$ & $0.59(0.19-0.33)$ \\
\hline & & $(0.0005-0.001)$ & $(0.002-0.003)$ & $(0.001-0.002)$ \\
\hline
\end{tabular}

CI: confidence internal. AIC Akaike information criterion. BIC: Bayesian Information Criterion

\section{Figures}

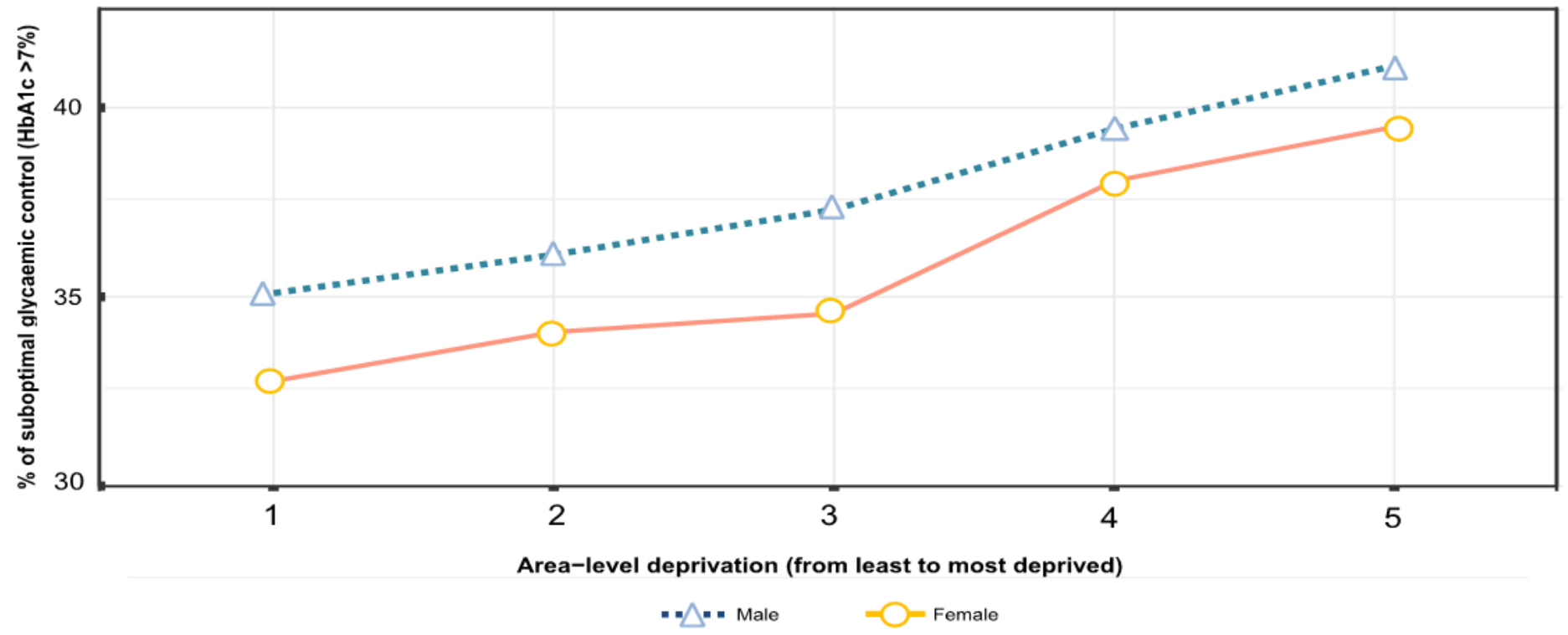

\section{Figure 1}

Glycaemic control by SES index and sex. 


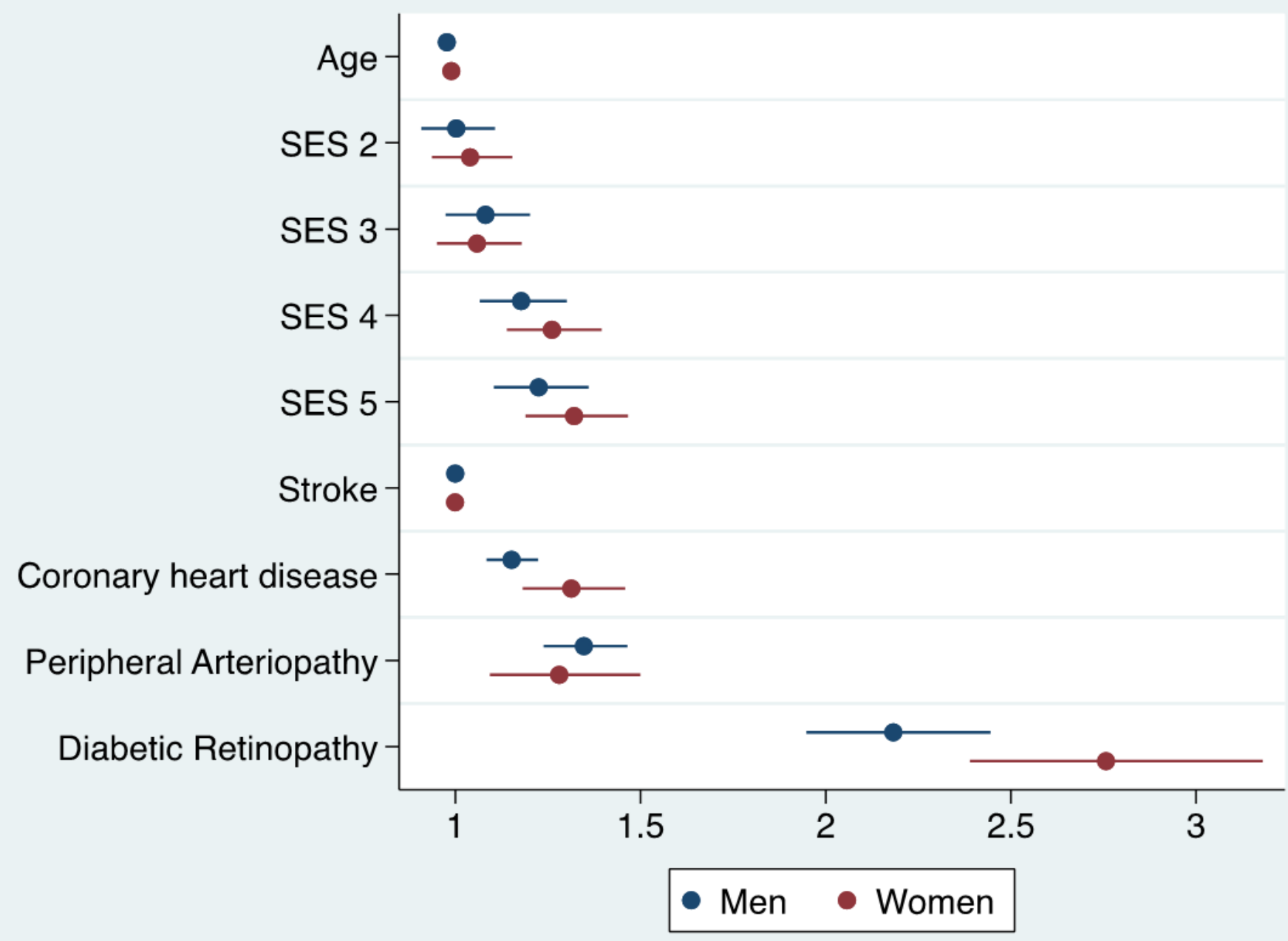

Figure 2

Main complications by sex.

\section{Supplementary Files}

This is a list of supplementary files associated with this preprint. Click to download.

- Additionalfiles.docx 